\title{
Effects of variation in food resources on foraging habitat use by wintering Hooded Cranes (Grus monacha)
}

Meng Zheng ${ }^{1,2,3}$, Lizhi Zhou ${ }^{1,2,3^{*}}$, Niannian Zhao ${ }^{4}$ and Wenbin $\mathrm{Xu}^{4}$

\begin{abstract}
Background: The ideal habitat use of waterbirds can be considered to be fixed, but current habitat use depends on environmental conditions, especially those of food characteristics, considered crucial to their use of habitats. Understanding how waterbirds respond to variation in food availability at degraded wetland sites and change their habitat use patterns over spatial and temporal scales should direct future conservation planning. The objectives of this study were to identify these spatial-temporal foraging habitat use patterns of Hooded Cranes (Grus monacha) and their relationship with food characteristics in the severely degraded wetlands of the Shengjin and Caizi lakes along with the Yangtze River floodplain.

Methods: We investigated the changes in food characteristics, relative abundance and density of Hooded Cranes in various habitat types across three winter periods from November 2012 to April 2013. We examined the effect of these winter periods and habitat types on the pattern of use by the cranes and explored the relationship between these patterns and food characteristics using linear regression.

Results: The food characteristics and habitat use clearly changed over spatial-temporal scales. In the early and mid-winter periods, the most abundant, accessible and frequented food resources were found in paddy fields, while in the late period the more abundant food were available in meadows, which then replaced the paddy fields. There were fewer effects of winter periods, habitat types and their interactions on habitat use patterns except for the effect of habitat types on the relative abundance, determined as a function of food abundance, but independent of food depth and sediment permeability.
\end{abstract}

Conclusions: In response to the degradation and loss of lake wetlands, the cranes shifted their habitat use patterns by making tradeoffs between food abundance and accessibility over spatial-temporal scales that facilitated their survival in the mosaic of these lake wetlands.

Keywords: Hooded Crane (Grus monacha), Habitat use, Food characteristics, Wintering ecology, Foraging habitat

\footnotetext{
* Correspondence: zhoulz@ahu.edu.cn

${ }^{1}$ School of Resources and Environmental Engineering, Anhui University, 111

Jiulong Road, Hefei 230601, China

${ }^{2}$ Institute of Biodiversity and Wetland Ecology, Anhui University, 111 Jiulong

Road, Hefei 230601, China

Full list of author information is available at the end of the article
} 


\section{Background}

Variety in spatial and temporal food resources plays an important role in habitat use patterns of many avian species (Newton 1998; Ackerman et al. 2006), adjusting their spatial behavior to complete their annual life history (Fox et al. 1998; Link et al. 2011; Zhao et al. 2013). In winter, food availability may be a particular constraint on habitat use by birds (Marra and Holberton 1998; Wang et al. 2013), because the food supply usually is at its lowest level (Moen 1976). Meanwhile, the urgent demand on nutrition and energy of avian species is to mediate the impact of bad weather conditions, habitat degradation and loss. For migratory waterbirds, habitat use patterns strongly affect the condition of their body, migration dates and a sequence of reproductive activities (Heaney and Monaghan 1996; Burger and Gochfeld 2013). Therefore, it is the responses to food constraints, such as the difference in quantity and quality within and between foraging patches across seasons, that impacts the spatial and temporal distribution and the sub-optimal foraging patch use of wintering waterbirds (Marra and Holberton 1998; Newton 2004).

Based on optimal foraging and ideal, free distribution (IFD) theories (Emlen 1966; Macarthur and Pianka 1966; Fretwell and Lucas 1969), the relationships of waterbirds and food resources should be close, when the waterbirds come across patches mirroring the variability of food availability (Nolet et al. 2002). However, food items are complex and while some food seems abundant, it may be inaccessible (Demment and van Soest 1985; Fryxell 1991; van Beest et al. 2010). A common framework for tradeoffs by wintering waterbirds is that they select high-quality food items with travel costs. Indeed, at a fine foraging scale, waterbirds typically make use of the more abundant food items with a consideration of their accessibility. Ultimately, the waterbirds would be faced with complex decisions about how to make use of patches over spatial and temporal scales. Their flexibility in habitat use patterns is therefore critical in coping with a changing ecosystem (Quaintenne et al. 2010; Amano 2012). In some highly dynamic ecosystems, such as river-lake wetland networks, the capacity for assessment and use of high-quality food items may be the essential adaptation once the optimal habitats are located, but there is less direct evidence that waterbirds have the capacity to adjust spatial behavior in real time in order to adapt to changing environments (Weimerskirch et al. 2003).

Lake wetlands, such as the middle and lower Yangtze River floodplains, form significant global networks (Chen et al. 2011; Zhao et al. 2013), containing abundant aquatic and biological resources and represent important wintering grounds supporting large numbers of wintering migratory waterbirds, including several endangered species (Cao et al. 2011; Chen et al. 2011). However, rising levels of human intervention and destruction over the last thirty years (Cao et al. 2011; Fox et al. 2011) are largely responsible for the increasing degeneration and loss of lake wetlands, resulting in the decline of suitable habitats for waterbirds in the Yangtze River floodplains (Zhou et al. 2010; Jia et al. 2013), possibly exerting far-reaching effects on the networks and services for waterbirds, which are experiencing dramatic changes in this ecosystem (Cao et al. 2011; Chen et al. 2011). The relationship between waterbirds, especially for migratory waders, in the fluctuations in hydrology and their food supply within or between patches across the seasons, has been enhanced and drawn increasing attention to wetland networks (Beerens et al. 2011; Link et al. 2011; Jia et al. 2013).

The Hooded Crane (Grus monacha) is a migratory wader in East Asia, breeding in forests and meadows in the Far East of Russia and the northeast of China (Meine and Archibald 1996; Zhou et al. 2010) and wintering in the wetlands of Korea, Japan and the middle and lower reaches of the Yangtze River in China (Ohsako 1994; Collar et al. 2001; Ma et al. 2003). It is a vulnerable (VU) species, classified as a first-class national protected wild animal in China's wildlife protection list (Meine and Archibald 1996; Zhou et al. 2010). The Chinese wintering populations are largely found in two adjacent shallow lakes, i.e., the Shengjin and Caizi lakes, in the middle and lower Yangtze River floodplains, which support two-thirds of the Chinese population (Ma et al. 2003; Zhou et al. 2010). In these lake wetlands, Vallisneria natans, Potamogeton malaianus and mollusks are the main food resources for the Hooded Crane. Owing to the degradation and loss of these lake wetlands, the cranes have changed their dietary structure (Zhou et al. 2010) and are declining in number (Harris et al. 2000; Zhao et al. 2013). Although some recent studies have revealed considerable flexibility in wader habitat use (Puglisi et al. 2005; White et al. 2006), including Grus species (Liu et al. 2010; Li et al. 2013), this flexibility of habitat use by larger migratory waders is regional and species-specific (Ma et al. 2003; Aborn 2010; Liu et al. 2010).

In the degraded lake wetlands, the foraging habitat use of Hooded Cranes should be more extensive, because the cranes have modified the patterns of foraging habitat use while expanding their home range and exploiting paddy fields for grain in response to the loss of natural foraging conditions since the start of the new millennium (Liu et al. 2001; Fox et al. 2011). Wetland degradation is spread worldwide, with significant number of waterbirds shifting their foraging habitat use (Jónsson and Afton 2006; Aborn 2010; Miller et al. 2010). Clearly, it is imperative to take appropriate conservation measures in the near future for several species, using the Hooded 
Crane as an example of how to modify their foraging habitat use patterns to cope with changes in food availability over spatial and temporal scales in response to the degradation and loss of wetlands.

Our study focused on the impact of the changes in food availability over spatial and temporal scales on the foraging habitat use patterns of wintering Hooded Cranes in the Yangtze River floodplain of the Anqing section. For the purpose of our study, we selected the two shallow lakes that have been exploited for a number of years for intensive fishery activities (Xu et al. 2008; Zhou et al. 2010). We specifically aimed to quantify the variation in the patterns of crane foraging habitat use over spatial-temporal scales and to evaluate the effect of food availability on these patterns. We hypothesize the cranes have the behavioral capacity to adapt to the habitat degeneration and losses while modifying the patterns over spatial-temporal scales.

\section{Methods}

Study area

Our study area consisted of the Shengjin $\left(30.27^{\circ}-30.47^{\circ} \mathrm{N}\right.$, $\left.116.98^{\circ}-117.21^{\circ} \mathrm{E}\right)$ and Caizi lakes $\left(30.75^{\circ}-30.97^{\circ} \mathrm{N}\right.$, $\left.117.00^{\circ}-117.15^{\circ} \mathrm{E}\right)$, two shallow lakes connected to the Yangtze River on the Eastern Asian-Australian flyway (Zhou et al. 2010; Fox et al. 2011; Chen et al. 2011). The region is the North subtropical humid monsoon climate, with an average annual temperature of $16.5-16.7^{\circ} \mathrm{C}$ and precipitation of 1291.33 to $1322.23 \mathrm{~mm}$. At no point of the year are the lakes completely frozen (Zhou et al. 2010). There is a clear separation between a rainy and a dry season; the rainy season lasts from April to October and the dry season is from November to the following March. The annual water level fluctuates with a rise when it rains and a drop during the dry season. In dry season large area of mudflats in the lake exposed to supply foraging habitats for the migratory waterbirds. Dominant plants in the lake are Potamogeton crispus, Ceratophyllum demersum and Carex thunbergii, while Potentilla supina, Polygonum criopolitanum and Ranunculus polii, among others, are associated plants (Fox et al. 2011). In recent years, the fish and crab aquaculture has resulted in the degradation of submerged vegetation in most of the lakes along the Yangtze River (Harris et al. 2000; Ma et al. 2003); in particular Vallisneria natans and Potamogeton malaianus are affected by a hydro-fluctuation belt (Chen et al. 2011). Some waterbirds have made use of paddy fields as foraging sites where the grains remaining after harvesting serve as a major food alternative (Tourenq et al. 2001).

Spatial-temporal fluctuations in food availability affect crane habitat use within the wetlands (Zhao et al. 2013). For the purposes of our study, the wintering periods were separately analyzed. According to the natural climate, hydrological processes and the migratory rhythm of the Hooded Crane, we distinguished three phases of the winter: November and December were considered the early wintering period; January and February of the following year constitute the middle wintering period and March and early April, the late wintering period. Similarly, based on the differences in vegetation and micro-geomorphic features, the foraging habitat patches were deliniated into three types, i.e., meadows, mudflats and paddy fields.

\section{Population survey}

Based on the type of foraging on the part of the crane in the two lake wetlands, where its foraging activity mainly occurred at six sites (consisting of three foraging types in each of the two lakes), we conducted weekly a crane population survey among these six sites along an approximate $2.5-\mathrm{km}$ route, from November 2012 to April 2013. Once we found a group of cranes, the entire visible part of the site was clockwise scanned using a monocular telescope (Swarovski, $30 \times 60$ ). We used a direct counting method to record the number of crane flocks, as well as the number of individual birds in each flocks. We conducted the crane population survey for sixteen rounds during the entire winter season. In order to reduce the effect of severe weather on our results, observations were postponed to the next day on days with strong winds, thick fogs, or heavy snow (Jia et al. 2013; Li et al. 2013). In total, 385 foraging flocks were observed and recorded.

\section{Food characteristics and foraging areas}

When we finished the crane counts, we conducted observations on the behavior of the cranes until they flew away. On the sites occupied by the cranes in their home ranges, we established quadrats of 100 by $100 \mathrm{~m}$; within these quadrats $10 \times 10 \mathrm{~m}$ sub-quadrats were randomly allocated and within each sub-quadrat, we set a further five $0.5 \times 0.5 \mathrm{~m}$ plots, one in the center and one in each of the four corners located by a handheld GPS(eTrex30, Garmin, China) (Ma et al. 2003; Thomas and Taylor 2006).

We collected data of the food items, including their abundance and accessibility. Given that the length of the bill of cranes is approximately $15 \mathrm{~cm}$ and that cranes exhibit a variety of foraging techniques (Jia et al. 2013), in each quadrat, we collected from each of these plots the tubers and roots of aquatic vegetation, such as those of Potentilla supine, Polygonum hydropiper, Ranunculus polii, Sagittaria sagittifolia, some other vegetable food items consumed by the Hooded Cranes (Zhao et al. 2013), entrails of mollusks and rice grains, within the typical $15 \mathrm{~cm}$ foraging depth constraint for Grus species of the foraging sediment (not including water depth) (Wang 1988; Jia et al. 2013). We dried these food items at $65^{\circ} \mathrm{C}$ in an oven (YHG-9050A; Derip, Suzhou, 
China) to a constant weight for $\geq 72 \mathrm{~h}$, which represented their dry weight (g). We defined the ratio of the dry weight of food resources in each plot over its area $\left(0.25 \mathrm{~m}^{2}\right)$ as the index of food abundance $\left(\mathrm{g} \cdot \mathrm{m}^{-2}\right)$. In order to examine the accessibility of food items, before we collected all of them, we measured the hardness of foraging sediment using a straightedge (TYD-2; Alisun, Hangzhou, China), inserted vertically into the sediment surface for a depth of $15 \mathrm{~cm}$; their peak value was recorded as sediment penetrability $\left(\mathrm{N} \cdot \mathrm{cm}^{-2}\right)$. As well, we measured food depth using a straightedge (Deli, Beijing, China) and recorded the thickness of the foraging sediment above the food items as food depth. During the winter seasons we collected information from a total of 420 plots, of which 45,40 and 40 were in the meadows, 50,55 and 40 in the mudflats, and 40, 45 and 65 in paddy fields, respectively from the early, mid-, to late wintering periods.

We located the plots, from where we collected these food characteristics, using a handheldGPS. In this way, each location was mapped with GPS into the MapInfo 8.5. Based on these locations, we calculated the foraging areas with the MapInfo 8.5. Across the winter, we identified the foraging habitat types used by the cranes and divided these foraging locations into crane foraging habitat types during each wintering period. The foraging areas were calculated by MapInfo 8.5 using a Minimum Convex Polygon Method (Reynolds 2004).

\section{Data analysis}

The foraging habitat used by Hooded Cranes was assessed on the basis of their spatial distribution. We calculated the relative abundance (\%) and density (ind. $\mathrm{km}^{-2}$ ) of cranes in each type of foraging habitat across the winter periods. Differences within or between foraging habitats indicated the changes in the use of the habitat by the cranes over spatial-temporal scales. We estimated the relative abundance of cranes in each habitat patch as the ratio of the number of cranes in the $i^{\text {th }}$ habitat type over the total number of cranes in all foraging habitat types during a specific period (Jing et al. 2007; Gyimesi et al. 2012), using the equation:

\section{Relative abundance $=N_{i} / N$}

where the "relative abundance" is the relative number of Hooded Cranes found in habitat type $i$ over all the individual cranes in the three habitat types during a period; $N_{i}$ is the recorded number of cranes in habitat type $i$ and $N$ the total number of cranes in the three habitats in each period.

To test for the density (ind. $\mathrm{km}^{-2}$ ) in the $i^{\text {th }}$ habitat, we calculated the density using the ratio of the number of cranes over the areas of the corresponding foraging habitat area. The equation is as follows:

$$
\text { Density }=N_{i} / S_{i}
$$

where the "density" is the number of cranes per unit area $\left(\mathrm{km}^{2}\right), N_{i}$ the recorded number of cranes and $S_{i}$ the habitat area of the crane foraging activities in the $i^{\text {th }}$ habitat type.

In order to examine the effect of the wintering periods and habitat types on the relative abundance and density of Hooded Cranes, we employed a general linear model to analyze this effect on the habitat use of the cranes and their interaction. A linear regression model was used to determine the correlation between the relative abundance and density of cranes and food characteristics, i.e., abundance, depth and sediment penetrability. Before the analysis these two variables were changed by a logarithmic transformation as $\log (X+1)$, where $X$ is either the relative abundance or density.

The Kolmogorov-Smirnov test was used to see whether the changes in the relative abundance and density within and between the different habitat types across the winter periods followed a Gaussian distribution. A one-way ANOVA was used to analyze the differences among the foraging habitat types and wintering periods, in the case they followed a Gaussian distribution. The nonparametric $U$ and $\chi^{2}$ test were used if the variables did not follow a Gaussian distribution.

All analyses were performed using PASW Statistics 18. A significance level of $(p) 0.05$ was used for all statistical tests, with results stated as mean $\pm \mathrm{SD}$.

\section{Results}

\section{Food characteristics and foraging areas}

The food characteristics and foraging areas were erratic on the grounds within the Shengjin and Caizi lakes across winter periods (Table 1). Food resources were most abundant in paddy fields $\left(56.54 \mathrm{~g} \cdot \mathrm{m}^{-2}\right)$ and least in the mudflats $\left(18.40 \mathrm{~g} \cdot \mathrm{m}^{-2}\right)$. Across the winter seasons, food resources decreased in the paddy fields and mudflats, but increased in the meadows, where food was significantly more abundant than in both the paddy fields and mudflats during the late wintering period $\left(\chi_{2}^{2}, 142=46.541\right.$, $p=0.000$ ). In this period, the food depth increased significantly in the mudflats and paddy fields (in mudflats and paddy fields, $\left(Z_{1,93}=-7.024, p=0.000 ; F_{1},{ }_{109}=79.626\right.$, $p=0.000$; respectively). The foraging sediment penetrability was maximum during the mid- winter period in the meadows and decreased significantly in late wintering period $\left(F_{1,78}=38.368, p=0.000\right)$, but it increased in the mudflats and paddy fields from the mid- to late periods (Table 1). The foraging habitat areas ranged from $3.88 \mathrm{~km}^{2}$ to $8.83 \mathrm{~km}^{2}$, with an average area of $5.24 \mathrm{~km}^{2}$. 
Table 1 Food variables (mean \pm SE) within different habitats and foraging areas across winter seasons within the Shengjin and Caizi lakes

\begin{tabular}{|c|c|c|c|c|c|}
\hline Habitat type & Period & Abundance $\left(\mathrm{g} \cdot \mathrm{m}^{-2}\right)$ & Depth $(\mathrm{cm})$ & Penetrability $\left(\mathrm{N} \cdot \mathrm{cm}^{-2}\right)$ & Foraging area $\left(\mathrm{km}^{2}\right)$ \\
\hline \multirow[t]{3}{*}{ Meadow } & Early & $46.74 \pm 6.17$ & $6.51 \pm 0.47$ & $247.20 \pm 4.60$ & 5.03 \\
\hline & Middle & $2932 \pm 5.85$ & $7.82 \pm 0.70$ & $290.63 \pm 5.02$ & 5.57 \\
\hline & Late & $82.75 \pm 10.44$ & $6.46 \pm 0.50$ & $219.41 \pm 9.95$ & 8.83 \\
\hline \multirow[t]{3}{*}{ Mudflat } & Early & $29.32 \pm 4.27$ & $5.13 \pm 0.52$ & $51.38 \pm 5.07$ & 3.88 \\
\hline & Middle & $18.08 \pm 3.67$ & $4.49 \pm 0.52$ & $141.82 \pm 8.36$ & 4.78 \\
\hline & Late & $7.79 \pm 1.84$ & $12.75 \pm 0.65$ & $87.16 \pm 6.96$ & 4.43 \\
\hline \multirow[t]{3}{*}{ Paddy field } & Early & $87.20 \pm 6.29$ & $3.94 \pm 0.39$ & $14.59 \pm 3.39$ & 4.36 \\
\hline & Middle & $54.84 \pm 5.69$ & $4.37 \pm 0.41$ & $22.06 \pm 2.98$ & 5.30 \\
\hline & Late & $27.58 \pm 4.33$ & $10.81 \pm 0.51$ & $114.71 \pm 6.58$ & 5.02 \\
\hline
\end{tabular}

\section{Foraging habitat use}

Across the seasons, the relative abundance and density of cranes in the meadows were $37.45 \%$, and 24.66 ind. $\mathrm{km}^{-2}$, in the mudflats $14.26 \%$ and 12.45 ind. $\mathrm{km}^{-2}$, and in the paddy fields $48.29 \%$, and 29.55 ind. $\mathrm{km}^{-2}$ respectively (Figures 1 and 2). The relative abundance and density initially decreased and then rapidly increased in the meadows, compared to the decrease from the early to mid- winter period; both the relative abundance and density of cranes increased significantly $(p<0.01)$. Both the relative abundance and density of cranes decreased continuously in the mudflats and paddy fields across the winter season, their decrease was relatively greater from the mid- to late period than in the early to mid- winter period in the paddy fields (Figures 1 and 2). The relative abundance decreased by $50.63 \%$ and the density decreased significantly $\left(Z_{1,51}=-4.615, p=0.000\right)$.

Changes in habitat types had a significant effect on the relative abundance of wintering cranes (Table 2). The

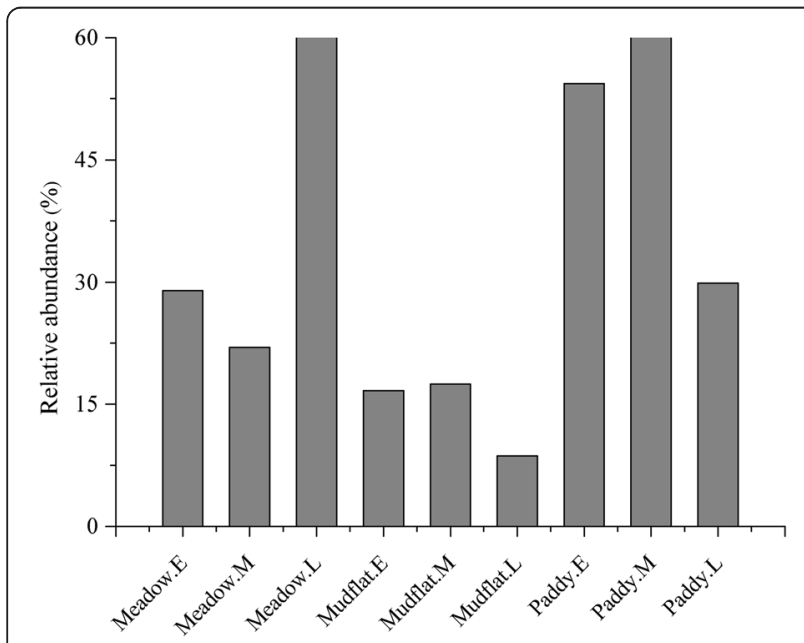

Figure 1 Relative abundance (\%) of Hooded Cranes in each habitat type across three winter periods. The ". $E$ ", ". $M$ " and ". $L$ " represent the early, middle and late wintering periods, respectively. fluctuation of the relative abundance and density of the cranes occurred within and among habitats across the winter season, while their density in the region did not vary with the changes in habitat types across the winter seasons. The change in seasons also had less effect on the relative abundance of the cranes (Table 2). It is to be noted that the interactive effect of wintering periods and habitat types on the relative abundance and density of the cranes were not significant (Table 2).

\section{Relationships foraging habitat use and food resources}

The relationships between food variables over all sampling habitat types and winter periods for the relative abundance and density of cranes were analyzed by fitting regression equations (Table 3, Figure 3). The relative abundance and density of Hooded Cranes were significantly affected by food abundance (Table 3, Figure 3), showing food abundance positively and significantly correlated with

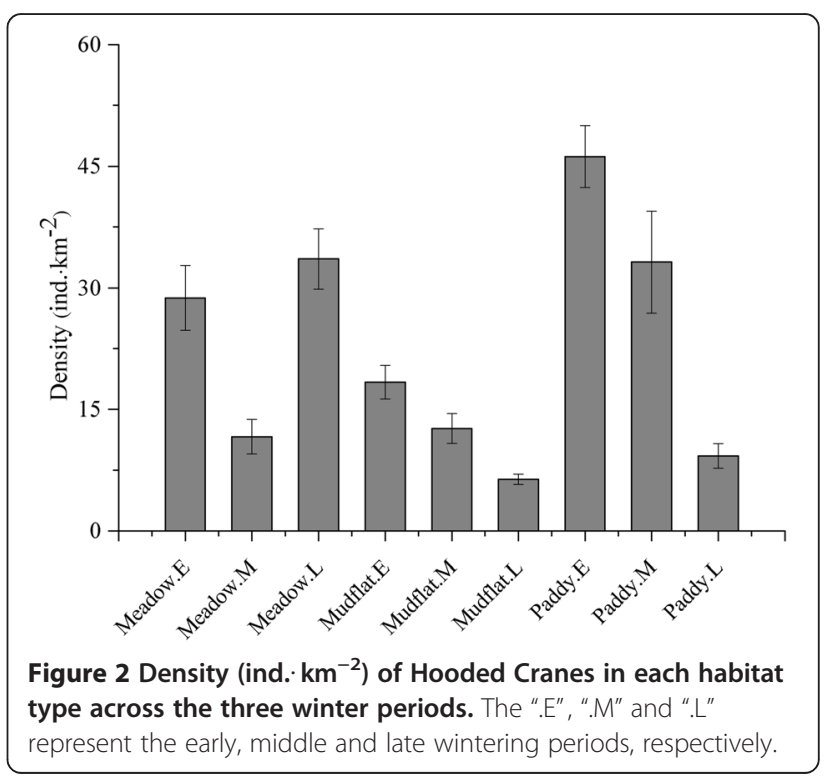


Table 2 Analysis of variance of the relative abundance (\%) and density(ind. $\mathrm{km}^{-2}$ ) of Hooded Cranes in relation to the winter periods and habitat differences $(n=18)$

\begin{tabular}{llllll}
\hline Effects & \multicolumn{2}{l}{ Relative abundance } & & \multicolumn{2}{c}{ Density } \\
\cline { 2 - 3 } & $\boldsymbol{F}$ & $\boldsymbol{p}$ & & $\boldsymbol{F}$ & $\boldsymbol{p}$ \\
\hline Period & 0.000 & 1.000 & & 1.150 & 0.359 \\
Habitat & 5.675 & 0.025 & & 1.992 & 0.192 \\
Period $\times$ Habitat & 0.606 & 0.669 & & 0.742 & 0.587 \\
\hline
\end{tabular}

the relative abundance and density of cranes; both, variables show an increase as a function of food abundance (Figure 3). On the other hand, food depth and sediment penetrability showed a negative but statistically not significant correlation with these two variables. The figures suggest that crane density and relative abundance are not dependent on food depth and sediment permeability.

\section{Discussion}

\section{Foraging habitat use patterns}

The food resources within the Shengjin and Caizi lakes varied over the spatio-temporal scale. This variation in food variables among habitat patches across the three winter periods has implications for the cranes, given that they had selected a series of foraging habitats and use strategies. Hooded Cranes, as tuber eating waterbirds, forage primarily in mudflats (Wang 1988; Harris et al. 2000; Ma et al. 2003), but when the amount and quality of food resources declines significantly, they find alternative food resources. The suitable patches also attract other foragers with a decrease in their food supply. It is therefore inevitable that differences in food items within or between foraging patches will lead to the differences in the foraging strategies among patches across the different wintering periods.

Our results indicated the Hooded Cranes have been quite flexible strategies in changing their foraging habitat use patterns over time and space in order to improve their fitness on their dwindling food resources. In a previous study Wang (1988) showed that the mudflats had adequate and accessible roots and tubers of submerged and floating-leave plants for their sustenance. As well, these mudflats are far away from villages and roads with less chance of human disturbances and the main foraging habitats used by Hooded Cranes (Wang 1988; Liu et al.2001). However, as a consequence of economic activities such as aquaculture, large amounts of roots and tubers of plants had been depleted in the past twenty years, and the mudflats no longer provide sufficient food for the cranes. The paddy fields and meadows, which contain relatively large amounts of food, had become major alternative foraging habitats. The similar changing habitat use patterns have also been observed in other Grus species such as the Sandhill (Grus canadensis), Common (Grus grus) and Black-necked (Grus nigricollis) cranes (Bishop and Li 2002; Alonso et al. 2004; Aborn 2010). These observations suggest that the Grus species have flexible habitat use strategies when they are confronted with the decline in the roots and tubers of plants in mudflats (Zhou et al. 2010; Fox et al. 2011) and shows that it is to the advantage of these wintering Grus species that they make increasing use of sub- optimal habitats (Fox et al. 2011; Zhao et al. 2013). In essence, the Hooded Cranes have changed their main foraging habitat to improve the energy and nutrient intake.

Although paddy fields and meadows turned out to be the main habitats used by cranes, their relative importance varied across wintering periods. Our results suggest that the cranes preferred paddy fields during the early and mid- wintering periods, as evidenced by their relatively high abundance and density and then shifted their main foraging habitat from paddy fields to meadows in the late winter period. In the early period, due to long distance migration, the cranes quickly need to obtain supplementary amounts of food as well as resilience. It is not necessarily by coincidence that large amounts of rice grains were scattered on the ground in the paddy fields, which provided for

Table 3 Effects of food avaibility on the use of foraging habitat by Hooded Cranes based on regression analysis

\begin{tabular}{lllr}
\hline Effect & Regression coefficient $( \pm$ SE) & Standardized regression coefficient & $\boldsymbol{t}$ \\
\hline Relative abundance (\%) & & & $\boldsymbol{p}$ \\
Constant & $1.070( \pm 0.297)$ & 0.616 & 3.623 \\
Abundance & $0.016( \pm 0.006)$ & -0.132 & 2.748 \\
Depth & $-0.009( \pm 0.015)$ & -0.090 & -0.600 \\
Permeability & $0.000( \pm 0.001)$ & & -0.473 \\
Density (ind. $\left.\mathbf{k m}^{-\mathbf{2}}\right)$ & & & 0.016 \\
Constant & $1.088( \pm 0.259)$ & 0.561 & 0.644 \\
Abundance & $0.013( \pm 0.005)$ & -0.176 & 0.206 \\
Depth & $-0.011( \pm 0.013)$ & -0.212 & 2.586 \\
Permeability & $0.000( \pm 0.001)$ & -0.828 & 0.022 \\
\hline
\end{tabular}

Estimates of relative abundance and density were carried out on $\log (X+1)$ transformed data. 

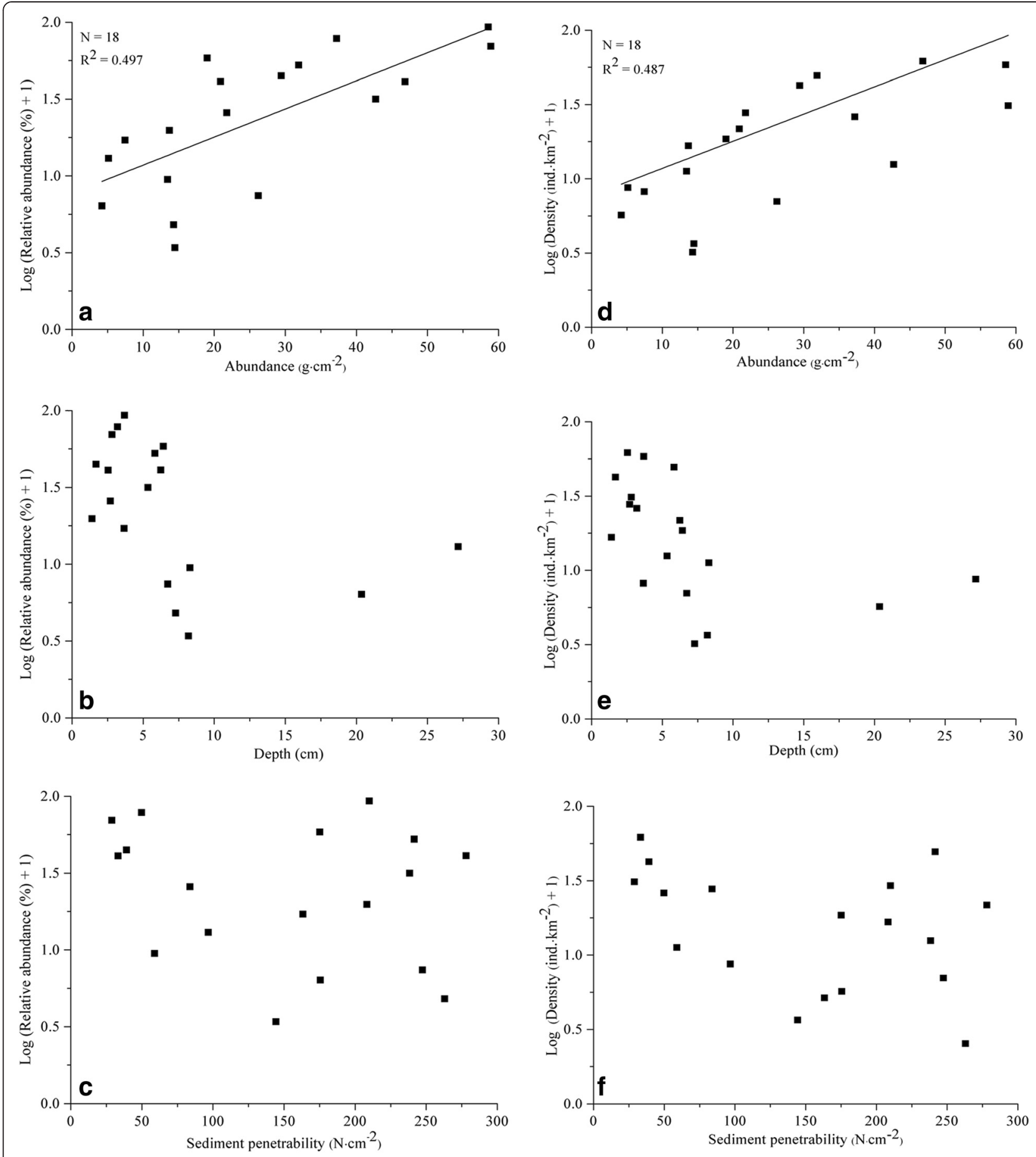

Figure 3 Effect of food characteristics on the relative abundance and density of Hooded Cranes within the Shengjin and Caizi lakes wetlands. a and $\mathbf{d}$ show a positive and significant linear relationship of both the relative abundance and density with food abundance $(r>0.5, p<0.05) ; \mathbf{b}, \mathbf{c}, \mathbf{e}$ and $\mathbf{f}$ show that the negative but not significant linear relationship both of the relative abundance and density with the food depth and sediment penetrability $(r<0.5, p>0.05)$.

quick, abundant, accessible and higher calorie intake (Eadie et al. 2008; Miller et al. 2010). The cranes would obtain the greatest benefits and expend the least foraging efforts when making use of paddy fields, despite needing to make trips across several patches. In the mid-winter period, the amounts of rice grains were small, but sufficient to support most of the cranes. In order to survive in this dry and cold climate, it is relatively more beneficial for the 
waterbirds to forage in the paddy fields (Fauchald et al. 2000; Elphick and Oring 2003; Eadie et al. 2008). However, in early spring, the plants grew rapidly and bloomed in the meadows (Xu et al. 2008), providing a significant increase in the quantity, quality and accessibility of food items, when the sediments were loose and could easily be excavated (Zhao et al. 2013). However, an opposite development occurred in the paddy fields in early spring because of food depletion and other factors, such as spring plowing (Bishop and Li 2002).

\section{Effects of food characteristics on foraging habitat use}

The cranes show great flexibility in their habitat use patterns in space and over time, given that they are true generalists and can modify these patterns depending on the differences of food characteristics. Our results suggest seasonal changes in their priorities in selecting food items and that dietary and habitat use are closely related to food characteristics. Abundance in food has frequently been considered one of the most critical factors to determine the distribution of birds (Strong and Sherry 2000; Jónsson and Afton 2006). The regression equations of the relative abundance and density are sufficiently strong to estimate the effect of food abundance. The food abundance is positively correlated with both variables. The Hooded Crane, as a large wader, expends considerable amounts of energy for survival and reproductive success (Fox et al. 2011; Zhao et al. 2013; Cai et al. 2014). Since the wetlands have become severely degraded, and given that Hooded Cranes prefer to forage in optimal habitats, most cranes flocked together with the consequence that competition for food created a zone of food depletion surrounding large crane colonies, producing the so-called Ashmole's halo (Ashmole 1963). Foraging time and energy expenditure increase, foraging efficiency would reduce and the dynamic effects of food abundance would be extended. Fortunately, the cranes adjusted with a spatial redistribution and made trips to mediate its effects while searching further afield for alternative food items.

Positive relationships between wader foraging habitat use and food abundance have also been found in other studies (Backwell et al. 1998; Folmer et al. 2010; Kuwae et al. 2010), while Lantz et al. (2011) and Beerens et al. (2011) argue that food accessibility is also important. It is more profitable for cranes to raise the benefits/cost ratio of food accessibility simultaneously while avoiding deeper food items and harder sediment (Kuwae et al. 2010; Baschuk et al. 2012; Clausen et al. 2012). Cranes also adopt effective strategies that protect their bills from wear and tear during the process of excavating, pecking and probing. However, the relative abundance and density are not closely related to and restricted by the depth of food and sediment permeability. Their various foraging techniques and powerful bills enable the cranes not only to pick up rice grains on the ground and probe mollusks under swamps, but also excavate the roots and tubers from the soil (Ohsako 1994; Liu et al. 2010; Jia et al. 2013). By consuming the various food items, cranes selectively exploit habitat from shallower and swampier sediments for more energy and nutrition intake with less foraging effort (Wang 1988; Liu et al. 2010). In our study area, the food depth was less than the extent of the crane bill. Therefore the spatial distribution of Hooded Cranes was not dependent on the accessibility of food items.

\section{Conservation implications}

Traditionally, mudflats in the hydro-fluctuation belts of our study area were the main foraging habitat of wintering cranes. However, anthropomorphic activities and destruction have caused severe degradation and loss of the suitable foraging habitats, resulting in a decrease in quantity and quality of food items. As a consequence, the mudflats could no longer support the cranes. In order to protect the wintering crane populations effectively, the ecological pressures caused by wetland degradation and loss need to be removed. The following steps should be strictly followed if we are to save the cranes: (a) to reduce the density of commercial fishery, particularly, herbivorous fish species and replant Vallisneria natans, Potamogeton malaianus, and other submerged plants in mudflats and shallow water patches to restore the ecosystem; (b) in order to ensure an adequate food supply from paddy fields, the area of spring plowing should be reduced, or else postponed until the cranes migrate and leave the region; (c) to perform proper artificial water replenishment for meadows in the dry winter season, especially in the mid- winter period and reduce the frequent interference and competition from grazing, and management in meadows.

\section{Conclusions}

Across the winter season, the cranes adjusted their main foraging habitat types with preferential changes in their foraging habitat. Their relative abundance and density were dynamic and ensured that the available food items were adequate and sufficiently accessible to the cranes. Given the spatial and temporal changes in food resources, especially food abundance, i.e., the determinant for cranes to modify their habitat use patterns, modification is a significant tactic for cranes to mitigate the dynamic effects of the food shortage in response to the degradation and loss of the lake wetlands. The findings of our study are mainly related to two aspects: (a) the cranes had alternative dietary patterns and habitats; (b) there were clear spatial and temporal changes in food resources, which ensured the seasonal presence of optimal habitats. Given their flexible habitat use patterns, cranes can easily exploit different food items with relatively greater profitability and less effort to improve the fitness of their population. 


\section{Competing interests}

The authors declare that they have no competing interests.

\section{Authors' contributions}

$M Z$ and LZ conceived and designed the experiments; MZ performed the experiments; $M Z$ and LZ analyzed the data; LZ contributed the reagents, the material and analytical tools; $M Z$ and $L Z$ wrote the paper; $L Z$ liaised with nature reserve authorities and obtained provincial guidance for field work. All the authors read and approved the final version of the manuscript.

\section{Acknowledgments}

This study was supported by the National Natural Science Foundation of China (Grant no. 31172117 and 31472020) and the Graduate Student Innovation Research Projects of Anhui University (YQ 01001770). We express appreciation to Dr. Chunlin Li and Lingzeng Meng for their helpful comments and suggestions on this study, as well as the staff of the Shengjin Lake National N. R. for their help with the fieldwork.

\section{Author details}

${ }^{1}$ School of Resources and Environmental Engineering, Anhui University, 111 Jiulong Road, Hefei 230601, China. ${ }^{2}$ Institute of Biodiversity and Wetland Ecology, Anhui University, 111 Jiulong Road, Hefei 230601, China. ${ }^{3}$ Anhui Biodiversity Information Center, 111 Jiulong Road, Hefei 230601, China. ${ }^{4}$ Shengjin Lake National Nature Reserve of Anhui Province, Dongzhi 247200, China.

\section{Received: 1 October 2014 Accepted: 16 April 2015}

\section{Published online: 01 July 2015}

\section{References}

Aborn DA (2010) Possible competition between waterfowl and Sandhill cranes at Hiwassee wildlife refuge, Tennessee. Proceedings of the North American Crane Workshop, In, pp 15-21

Ackerman JT, Takekawa JY, Orthmeyer DL, Fleskes JP, Yee JL, Kruse KL (2006) Spatial use by wintering Greater white-fronted geese relative to a decade of habitat change in California's central valley. J Wildlife Manage 70(4):965-976

Alonso JC, Bautista LM, Alonso JA (2004) Family-based territoriality vs flocking in wintering Common cranes Grus grus. J Avian Biol 35(5):434-444

Amano T (2012) Unravelling the dynamics of organisms in a changing world using ecological modelling. Ecol Res 27(3):495-507

Ashmole NP (1963) The regulation of numbers of tropical oceanic birds. Ibis $103 \mathrm{~b}(3): 458-473$

Backwell PR, O'hara PD, Christy JH (1998) Prey availability and selective foraging in shorebirds. Anim Behav 55(6):1659-1667

Baschuk MS, Koper N, Wrubleski DA, Goldsborough G (2012) Effects of water depth, cover and food resources on habitat use of marsh birds and waterfowl in boreal wetlands of Manitoba, Canada. Waterbirds 35(1):44-55

Beerens JM, Gawlik DE, Herring G, Cook MI (2011) Dynamic habitat selection by two wading bird species with divergent foraging strategies in a seasonally fluctuating wetland. Auk 128(4):651-662

Bishop MA, Li F (2002) Effects of farming practices in Tibet on wintering Black-necked Crane (Grus nigricollis) diet and food availability. Biodivers Sci 10(4):393-398

Burger J, Gochfeld M (2013) Wood Storks (Mycteria americana) prey on eggs and hatchlings of Olive ridley sea turtles (Lepidochelys olivacea) at Ostional, Costa Rica. Waterbirds 36(3):358-363

Cai T, Huettmann F, Guo Y (2014) Using stochastic gradient boosting to infer stopover habitat selection and distribution of Hooded Cranes Grus monacha during spring migration in Lindian, Northeast China. PLoS One 9(2), e89913

Cao L, Mark B, Zhao M, Meng H, Zhang Y (2011) A systematic scheme for monitoring waterbird populations at Shengjin Lake, China: methodology and preliminary results. Chinese Birds 2(1):1-17

Chen JY, Zhou LZ, Zhou B, Xu RX, Zhu WZ, Xu WB (2011) Seasonal dynamics of wintering waterbirds in two shallow lakes along Yangtze River in Anhui Province. Zoolog Res 32(5):540-548

Clausen KK, Clausen P, Fælled CC, Mouritsen KN (2012) Energetic consequences of a major change in habitat use: endangered Brent geese Branta bernicla hrota losing their main food resource. Ibis 154(4):803-814

Collar NJ, Crosby R, Crosby M (2001) Threatened Birds of Asia: the BirdLife International Red Data Book, vol 1. BirdLife International, Cambridge, UK
Demment MW, van Soest PJ (1985) A nutritional explanation for body-size patterns of ruminant and nonruminant herbivores. Am Nat 125(5):641-672

Eadie J, Elphick C, Reinecke K, Miller M, Manley S (2008) Wildlife values of North American ricelands. In: Manley SW (ed) Conservation in Ricelands of North America. The Rice Foundation, Stuttgart, Arkansas, pp 7-90

Elphick CS, Oring LW (2003) Conservation implications of flooding rice fields on winter waterbird communities. Agr Ecosyst Environ 94(1):17-29

Emlen JM (1966) The role of time and energy in food preference. Am Nat 100:611-617

Fauchald P, Erikstad KE, Skarsfjord H (2000) Scale-dependent predator-prey interactions: the hierarchical spatial distribution of seabirds and prey. Ecology 81(3):773-783

Folmer EO, Olff H, Piersma T (2010) How well do food distributions predict spatial distributions of shorebirds with different degrees of self-organization? J Anim Ecol 79(4):747-756

Fox AD, Kahlert J, Ettrup H (1998) Diet and habitat use of moulting Greylag geese Anser anser on the Danish island of Saltholm. Ibis 140(4):676-683

Fox AD, Cao L, Zhang Y, Barter M, Zhao MJ, Meng FJ, Wang SL (2011) Declines in the tuber-feeding waterbird guild at Shengjin Lake National Nature Reserve, China - a barometer of submerged macrophyte collapse. Aquat Conserv 21(1):82-91

Fretwell S, Lucas HL (1969) On territorial behavior and other factors influencing habitat distribution in birds. Acta Biotheor 19(1):16-36

Fryxell JM (1991) Forage quality and aggregation by large herbivores. Am Nat 138(2):478-498

Gyimesi A, Franken MS, Feige N, Nolet BA (2012) Human disturbance of Bewick's swans is reflected in giving-up net energy intake rate, but not in giving-up food density. Ibis 154(4):781-790

Harris J, Su LY, Higuchi H, Ueta M, Zhang ZW, Zhang YY, Ni XJ (2000) Migratory stopover and wintering locations in eastern China used by White-naped Cranes Grus vipio and Hooded Cranes G. monacha, as determined by satellite tracking. Forktail 16:93-99

Heaney V, Monaghan P (1996) Optimal allocation of effort between reproductive phases: the trade-off between incubation costs and subsequent brood rearing capacity. P Roy Soc B-Biol Sci 263(1377):1719-1724

Jia Y, Jiao S, Zhang Y, Zhou Y, Lei G, Liu G (2013) Diet shift and its impact on foraging behavior of Siberian crane (Grus leucogeranus) in Poyang Lake. PLoS One 8(6), e65843

Jing K, Ma Z, Li B, Li J, Chen J (2007) Foraging strategies involved in habitat use of shorebirds at the intertidal area of Chongming Dongtan, China. Eco Res 22(4):559-570

Jónsson JE, Afton AD (2006) Different time and energy budgets of Lesser snow geese in rice-prairies and coastal marshes in Southwest Louisiana. Waterbirds 29(4):451-458

Kuwae T, Miyoshi E, Sassa S, Watabe Y (2010) Foraging mode shift in varying environmental conditions by dunlin Calidris alpina. Mar Ecol Prog Ser 406:281-289

Lantz SM, Gawlik DE, Cook MI (2011) The effects of water depth and emergent vegetation on foraging success and habitat selection of wading birds in the Everglades. Waterbirds 34(4):439-447

Li Z, Wang Z, Ge C (2013) Time budgets of wintering Red-crowned cranes: effects of habitat, age and family size. Wetlands 33(2):227-232

Link PT, Afton AD, Cox RR, Davis BE (2011) Use of habitats by female mallards wintering in southwestern Louisiana. Waterbirds 34(4):429-438

Liu Q, Yang J, Yang X, Zhao J, Yu H (2010) Foraging habitats and utilization distributions of Black-necked cranes wintering at the Napahai Wetland, China. J Field Ornithol 81(1):21-30

Liu ZY, Xu WB, Wang QS, Shi KC, Xu JS, Yu GQ (2001) Environmental carrying capacity for overwintering Hooded Cranes in Shenjin Lake. Resources and Environment in the Yangtze Basin 10(5):454-459

Ma Z, Li B, Jing K, Zhao B, Tang S, Chen J (2003) Effects of tidewater on the feeding ecology of Hooded Crane (Grus monacha) and conservation of their wintering habitats at Chongming Dongtan, China. Ecol Res 18(3):321-329

MacArthur RH, Pianka ER (1966) On optimal use of a patchy environment. Am Nat 100(916):603-609

Marra PP, Holberton RL (1998) Corticosterone levels as indicators of habitat quality: Effects of habitat segregation in a migratory bird during the non-breeding season. Oecologia 116:284-292

Meine CD, Archibald GW (1996) The Cranes: Status Survey and Conservation Action Plan. IUCN, Gland, Switzerland, and Cambridge, U.K. 
Miller M, Garr J, Coates P (2010) Changes in the status of harvested rice fields in the Sacramento Valley, California: implications for wintering waterfowl. Wetlands 30(5):939-947

Moen AN (1976) Energy conservation by White-tailed deer in the winter. Ecology 57:192-198

Newton I (1998) Population Limitation in Birds. Academic, San Diego

Newton I (2004) Population limitation in migrants. Ibis 146(2):197-226

Nolet BA, Bevan RM, Klaassen M, Langevoord O, van Der Heijden YGJT (2002) Habitat switching by Bewick's swans: maximization of average long-term energy gain? J Anim Ecol 71(6):979-993

Ohsako Y (1994) Analysis of crane population change, habitat selection, and human disturbance in Japan. In: Higuchi H, Miton J (eds) The Future of Cranes and Wetlands. Wilde Bird Society of Japan, Tokyo, pp 107-113

Puglisi L, Claudia Adamo M, Emilio Baldaccini N (2005) Man-induced habitat changes and sensitive species: a GIS approach to the Eurasian bittern (Botaurus stellaris) distribution in a Mediterranean wetland. Biodivers Conserv 14(8):1909-1922

Quaintenne G, Van Gils JA, Bocher P, Dekinga A, Piersma T (2010) Diet selection in a molluscivore shorebird across Western Europe: does it show short- or long-term intake rate- maximization? J Anim Ecol 79(1):53-62

Reynolds MH (2004) Habitat use and home range of the Laysan Teal on Laysan Island, Hawaii. Waterbirds 27(2):183-192

Strong AM, Sherry TW (2000) Habitat-specific effects of food abundance on the condition of Ovenbirds wintering in Jamaica. J Anim Ecol 69:883-895

Thomas DL, Taylor EJ (2006) Study designs and tests for comparing resource use and availability II. J Wildlife Manage 70(2):324-336

Tourenq C, Bennetts RE, Kowalski H, Vialet E, Lucchesi J-L, Kayser Y, Isenmann P (2001) Are ricefields a good alternative to natural marshes for waterbird communities in the Camargue, southern France? Biol Conserv 100(3):335-343

van Beest FM, Mysterud A, Loe LE, Milner JM (2010) Forage quantity, quality and depletion as scale-dependent mechanisms driving habitat selection of a large browsing herbivore. J Anim Ecol 79(4):910-922

Wang Q (1988) Hooded Crane (Grus monacha). Chin J Zool 23(4):30-39

Wang X, Fox AD, Cong P, Cao L (2013) Food constraints explain the restricted distribution of wintering Lesser white-fronted Geese Anser erythropus in China. Ibis 155(3):576-592

Weimerskirch H, Ancel A, Caloin M, Zahariev A, Spagiari J, Kersten M, Chastel O (2003) Foraging efficiency and adjustment of energy expenditure in a pelagic seabird provisioning its chick. J Anim Ecol 72(3):500-508

White G, Purps J, Alsbury S (2006) The Bittern in Europe: a Guide to Species and Habitat Management. Royal Society for the Protection of Birds. Sandy, Utah, U.S.

Xu L, Xu W, Sun Q, Zhou Z, Shen J, Zhao X (2008) Flora and vegetation in Shengjin Lake. J Wuhan Botanical Res 27(3):264-270

Zhao F, Zhou L, Xu W (2013) Habitat utilization and resource partitioning of wintering Hooded Cranes and three goose species at Shengjin Lake. Chinese Birds 4(4):281-290

Zhou B, Zhou L, Chen J, Cheng Y, Xu W (2010) Diurnal time-activity budgets of wintering Hooded Cranes (Grus monacha) in Shengjin Lake, China. Waterbirds 33(1):110-115

\section{Submit your next manuscript to BioMed Central and take full advantage of:}

- Convenient online submission

- Thorough peer review

- No space constraints or color figure charges

- Immediate publication on acceptance

- Inclusion in PubMed, CAS, Scopus and Google Scholar

- Research which is freely available for redistribution

Submit your manuscript at www.biomedcentral.com/submit 